\title{
Lab relocation roulette: it's your move
}

\author{
Richard Sayre \\ Whether your lab lease has expired or it's simply time for more space, moving entails more than just boxes and \\ duct tape.
}

Dater uring my career as a research scientist and entrepreneur, I've had to move several times. My first experience was a disaster-literally. We had a lab fire while I was a postdoc at Harvard University in Cambridge, Massachusetts, and we had to relocate to another floor in the building. In a way, though, that fire had a silver lining: not only did I learn to take precautions to avoid future fires, but also I discovered how to break down and re-create a lab with maximum efficiency and minimal disruption. As a result, I was prepared for the logistics and processes involved in setting up a new lab when I moved to Ohio State University (OSU) in Columbus; indeed, I got my lab up and fully operational within two months.

Recently, I was on the move again, relocating my 2,000-square-foot plant molecular biology lab from OSU to The Donald Danforth Plant Science Center in St. Louis, Missouri. Soon, I will also move my company, Phycal, to the new Bio-Research \& Development Growth (BRDG) Park at the Danforth Center. What I've learned through all this is that whether you are moving an established lab or a fledgling company, you must concentrate on two areas to make the move go smoothly: organizing the lab on both ends of the actual event and choosing the mover.

\section{Putting your house in order}

A lab usually represents years of work and insights, as well as many thousands of dollars, not to mention the expense and generation

Richard Sayre is director of the Enterprise Rent-A-Car Institute for Renewable Fuels, The Donald Danforth Plant Science Center campus, St. Louis, Missouri, USA. He also is president of Phycal, Bio-Research \& Development Growth (BRDG) Park, The Donald Danforth Plant Science Center campus, St. Louis, Missouri, USA. e-mail: rsayre@danforthcenter.org

\section{Box 1 It's alive}

Not every moving company is qualified to handle a research lab, especially when it involves cryogenic or other biomaterials. Special training is necessary to comply with a multitude of requirements that range from how materials are packed to how they are loaded onto the truck. In addition, the lab must be prepared to spend the time necessary to provide as much detail as possible to the mover about every item to be transported, as well as all special requirements.

For example, my lab relocation required 15 pages itemizing every living plant specimen being transported. It also required two trailers with electricity to maintain a temperaturecontrolled environment for freezers and incubators, and hourly en route monitoring of temperatures.

For transgenic and biomaterials labs, in which temperature control is critical, there is absolutely no room for error. Many organisms have strict temperature and growth environment requirements, and bacterial strains harboring plasmids are often stored as frozen stocks. The microalgae used in my lab, for example, will survive only in a narrow temperature range between $5-30{ }^{\circ} \mathrm{C}$. Plants and algal cultures also may require illumination for extended transportation intervals. In addition, because our move involved transgenic materials, permits were required in advance from the Animal and Plant Health Inspection Service division of the United States Department of Agriculture, which also conducted an inspection after the move.

of results from the lab and its technicians. A disruption could be disastrous, so any move is a potential cause for anxiety. Whether a lab is moving down one floor in the same building, to another side of town or across a country, start by leaving nothing to chance and being organized.

Organizing begins with assigning every individual a specific task for moving into the new lab and for shutting down the old space. That includes more than the lab technicians-it means lab administrators and office administrators too, because even a simple move can involve more than a dozen people. Tasks can be everything from washing and drying beakers, test tubes and magnifying lenses to taking out the trash, and having each task assigned can make the process go more smoothly. One group might be responsible for packing and shipping frozen items, whereas another might manage the shipment of instruments used on a daily basis, and others might handle shipping special biological materials (moving biomaterials is a whole separate endeavor; Box 1).

The first step of packing up the old lab is formulating a detailed timeline. You should put down, in writing, the schedule for cataloging, packing, shipping or moving every single item in the lab. Every piece of equipment and every instrument needs to be itemized, each individual specimen labeled. Where are the research files, for instance, and when do they get packed? No amount of detail is too much to anticipate and plan for, from coordinating shipment and delivery of perishable materials to breaking down boxes.

The timeline should also include anticipating and initiating the regulatory process for any permits, clearances or permissions that may be required from local, state or national government at both ends of the move. Keep in mind that regulatory agencies often move at their own 


\section{Table 1 Relocation tips}

Do

Plan several months ahead

Get several bids from moving companies

Check all potential movers' references

Establish timelines

Back up all specimens

Assign a chief point person at both ends

Have people at the new lab in advance

Segregate everything to be moved from items to be

left behind

Take time to fill out the mover's questionnaire
Don't

Overlook regulatory permits, clearances, etc.

Assume your new building has an elevator

Wait to find out if the loading dock is inadequate

Forget to plan for shutting down the old lab

Hire a mover based on price alone

Forget about household moves for personnel pace, and the transfer of permits can be slower than anticipated. A good source of information regarding requirements may be available from facility managers at both locations, as well as from your industry trade association.

It's also key (and polite) to leave your old lab in good form for the new tenant. When we left OSU, we wanted our former space to look great, so we stopped all research and began an organized clean up 10 days in advance of our move. We made the cleanup as systematic as every other step, with each individual being assigned a specific task.

On the other end, being able to resume research as quickly as possible is the trickiest part of any move. For my lab, we ran several trial-and-error tests four to six weeks in advance of our actual move to determine just the right amount of dry ice and packing materials we needed to achieve the optimum temperatures for shipping frozen samples to the new lab. And, as a precaution, when you move, make sure you have backups for every specimen.

If you are planning on new equipment for your move, make sure to preorder - that way it arrives before you do and can be set up. We relocated several members of our team early so they could receive samples and equipment at the new lab before the rest of us (and the movers) arrived. As a result, the new lab was up and running in one week.

Make sure you find out in advance about state laws and permits required for moving. Moving chemical, biochemical and physics labs, for instance, can involve important legal and public safety issues. It is never too early to start navigating the myriad of federal, state and local laws. For transgenic plant materials, the United States Department of Agriculture's Animal and Plant Health Inspection Service in Washington, DC, has jurisdiction. Another good source of information is the research park management or university lab managers.

Once the move is over, you'll need to calibrate all your equipment, so make sure to consider these expenses when putting together your moving budget. Moving a lab is like moving a living organism because everything that happens during the move can impact everything else.

Finally, you should establish robust communications with the destination institution or facility to ensure that all the requisite spaces and infrastructure requirements are ready to receive you. This includes being prepared to receive and appropriately store shipments of specimens and equipment sent in advance, as well as being ready on move-in day. Also, make sure you know minute details, such as the specifications for the departure dock at the old lab and the receiving dock at the new destination. Without knowing this, you are taking your chances.

\section{Choosing the right mover}

There's a list of things you should (and shouldn't) do if you want your move to go smoothly (Table 1), and finding the right mover is one of them. Working with professional movers that have the right training and experience requires meticulously researching options and finding a mover that is qualified to transport biomaterials, if needed.

First, choose carriers that have extensive documented experience moving labs. Get references from other science labs to evaluate movers. When hazardous materials are involved, transportation can become very technical, and you might need specialized trailers to handle scientific instruments. Laboratory hazards are as varied as the subjects of study and might include poisons; infectious agents; flammable, explosive or radioactive materials; machinery with moving parts; and items that require extreme temperatures, strong magnetic fields or high voltage. Because of the level of specialization needed for different types of equipment and materials, your movers might need to be highly trained, and not every mover is qualified. So choose a company that has a dedicated team of specially trained representatives and a fully developed set of internal standards and practices for laboratory moves. You should ask whether services include arranging specialized providers, if that's required for your material, because when temperature control is necessary, attention to every detail is critical.

Once selected, the mover should begin by making a detailed assessment that includes understanding the kind of research your lab does, as well as what the physical move will involve in terms of equipment, specimens and other items. The mover should gather detailed information with a questionnaire that covers the nature of the materials to be transported and the packing methods that will help prevent damage during transit.

The movers should ask you the preferred method and type of cooling, if required, and about the necessity of monitoring and documenting temperatures. They should ask you about the specific types of plugs and receptacles needed. Other questions should determine if teams of drivers are required to maintain a 24-hour driving schedule, if there are any specific security concerns, if special rigging or tilt devices might be required and if a continuously monitored temperature-controlled environment is necessary.

The mover also should consider how logistics will impact the move at both ends. This includes anticipating any limitations, such as labs that are located in older buildings with no loading docks or no direct driveway access.

Some companies, such as Stevens Moving Company in Philadelphia, which we used for the move from OSU to Danforth, recommend choosing a mover at least four to six weeks in advance because the more notice you give, the better suited the moving company will be to accommodate your every request. Also consider St. Louis, Missouri-based UniGroup, the parent company of United Van Lines and Mayflower Transit, which has a Worldwide Specialty Logistics division with experience coordinating laboratory moves nationwide for universities, medical facilities, data centers and other similar institutions. When soliciting bids, make sure you offer the same information to each company so they can provide an accurate estimate of costs.

Although the time of year probably won't affect the price for your lab move, the summer is peak season (many university lab moves are tied to the academic year), and reserving special equipment and transportation vehicles should be done as far in advance as possible to ensure availability. Even so, the price for moving employees and their families may be higher in the summer, which is also peak season. Although it may be possible to successfully organize a move starting six weeks in advance, beginning three months in advance by getting bids, selecting a moving company and developing detailed lists of items to be moved and 
individual responsibilities can go a long way in minimizing last-minute problems.

Last but not least, movers are required by law to give you a copy of the Federal Motor Carrier Safety Administration's booklet Your Rights and Responsibilities When You Move. Additional information on how to choose a moving company is available at the Federal Motor Carrier Safety Administration's website (http://www.protectyourmove.gov). The site provides the latest information on how to plan a move, where to register a complaint against a moving company or drivers, and links to useful information at the state level.

\section{Parting thoughts}

There is no question that moving is a stressful experience for everyone involved. Although it is possible to establish timelines, make lists and check off completed items that pertain to the physical move, it is equally important to consider the emotional component of the move. Establishing a sense of camaraderie and mutual respect, and acknowledging everyone's individual efforts, will leave everyone feeling happier and more satisfied with the results, including yourself. Moving is usually associated with a new and exciting opportunity_taking the time to plan it correctly will make it a much more enjoyable experience. 